\title{
Corrosion Inhibition Performance of a Novel Cationic Surfactant for protection of Carbon Steel Pipeline in Acidic Media
}

\author{
M.A. Hegazy ${ }^{1}$, M. Abdallah ${ }^{2,3,}{ }^{*}$, M. Alfakeer ${ }^{4}$, H. Ahmed ${ }^{3}$ \\ ${ }^{1}$ Egyptian Petroleum Research Institute (EPRI), Nasr City, Cairo, Egypt \\ ${ }^{2}$ Chemistry Department, Faculty of Applied Sciences, Umm Al-Qura University, Makkah, Saudi Arabia \\ ${ }^{3}$ Chemistry Dept., Faculty of Science, Benha University, Benha, Egypt \\ ${ }^{4}$ Chemistry Dept., Faculty of Science, Princess Nourah bint Abdulrahman University -Riyadh, Saudi Arabia \\ *E-mail: metwally555@yahoo.com
}

doi: $10.20964 / 2018.07 .53$

Received: 18 March 2018 / Accepted: 6 May 2018 / Published: 5 June 2018

\begin{abstract}
The corrosion inhibiting action of a novel cationic surfactant on the dissolution of carbon steel (Csteel) in $1 \mathrm{M} \mathrm{HCl}$ has been investigated using weight loss, electrochemical impedance spectroscopy and potentiodynamic polarization techniques. The effect of inhibitor concentration and temperature on the corrosion rate of $\mathrm{C}$-steel was determined from weight loss approach. While the electrochemical and potentiodynamic measurements were used to explain the behavior of C-steel at a temperature $20{ }^{\circ} \mathrm{C}$. Adsorption of the cationic surfactant on the surface of the $\mathrm{C}$-steel pipeline is a mixture of physical and chemical adsorption and obeys Langmuir isotherm. The thermodynamic data of activation and adsorption were calculated and explained.
\end{abstract}

Keywords: C-steel; cationic surfactant, Adsorption; corrosion inhibitors; Interfaces

\section{$\underline{\text { FULL TEXT }}$}

(C) 2018 The Authors. Published by ESG (www.electrochemsci.org). This article is an open access article distributed under the terms and conditions of the Creative Commons Attribution license (http://creativecommons.org/licenses/by/4.0/). 